\title{
Impact of narcissistic personality disorder on cognitive organizational cynicism with mediating role of psychological capital in selected hospitals of Punjab Pakistan
}

\author{
Irfan Sabir ${ }^{1}$, Shahbaz Hussain ${ }^{2}$, Muhammad Bilal Majid ${ }^{3 *}$, Asad-ur Rehman $^{3}$, Arslan Sarwar ${ }^{3}$ and Farooq Nawaz ${ }^{2}$
}

\begin{abstract}
Purpose: The purpose of this research work was to analyze the narcissism personality disorder in nurses and their impact on cognitive organizational cynicism with mediating role of psychological capital.

Design/methodology/approach: In the current study, constructs developed from existing theories, generate hypotheses, adopt strategies for data collection and perform test to prove the proposed hypothesis. The nursing carder is the unit of analysis in this research study. Descriptive statistics, correction, and mediation analysis through Baron and Kenny's were performed for analysis.

Findings: This research concludes narcissism personality disorder has significant positive association with cognitive organizational cynicism. The role of psychological capital is mediating to minimize the negative employee's behavior toward their bosses and organization.
\end{abstract}

Practical implications: In the light of findings, the current research work has implications at individual and organization levels. This research work will become as foundation stone to formulate strategies to overcome the organization cynicism in nursing profession. Furthermore, the organization formulates selection process more affective to find those candidates having narcissism disorder.

Originality/value: The current research work is designated first study to evaluate the relationship between narcissistic personality disorder and cognitive organization cynicism with mediating role of psychological capital in Pakistan.

Keywords: Narcissistic personality disorder, Cognitive organizational cynicism, Psychological capital and hospitals of Punjab Pakistan

\section{Introduction}

\section{Background of the research}

The main attributes of narcissism are the personal admiration, delicate, privilege, dominance, and unfriendliness. The narcissism persons have the tendency to self-encouragement and self-suggestions but manipulate the outcomes to maintain their position. The research study

\footnotetext{
*Correspondence: bilalmajid34@gmail.com

${ }^{3}$ Universiti Sultan Zainal Abidin (UniSZA), Gong Badak Campus,

21300 Kuala Nerus, Terengganu, Malaysia

Full list of author information is available at the end of the article
}

of Erkutlu and Chafra [15] examined the association between leader narcissism and organization cynicism with mediation role of psychological strain and moderating role of psychological capital. The outcomes depicted that leader's narcissism and employee's organization cynicism have positive relationship. The role of psychological capital was strongly moderating when relationship between narcissism and cynicism was weak.

Aslam et al. [3] conducted a case research design to find out the effect of cynicism on personal behavior, job upshot and organizational related aspects. The findings 
depicted that there was considerably positive association between all study variables in direct and indirect models. The research work of Bell [6] studied the narcissism and cynicism as considerable inhibitor of gratitude and individual behavior. The results suggested that over time the combined effect of narcissism and cynicism reduces the density of grateful experiences. Kalağan and Aksu [24] studied the organizational cynicism within three subscales: cognitive, affective, and behavioral. The outcomes showed that the perceptions of organizational cynicism was different at various sub-scale level; at cognitive level, the cynicism was high, and at affective level, cynicism was lower. The cynicism state occurs when individual employee believes that organization has different problems and his personal efforts are useless to overcome these problems. Issık [21] stated that cynicism is coupled with lack of integrity which will leads to a negative powerful emotional reaction then leads to critical behavior.

Çinar et al. [11] studied the relationship among organizational cynicism, turnover intention, and job insecurity. The findings suggested that higher organizational cynicism has higher level of turnover intention and job insecurity. Ackerman et al. [1] studied the dimensions of Narcissism Personality Inventory (NPI). NPI was subdivided into normal narcissism and maladaptive narcissism. The normal aspects of NPI are social potency, extraversion, global self-esteem, goal persistence, and contingent self-esteem. The maladaptive narcissism aspects are anti-social tendencies, Machiavellianism, exploitativeness, devaluing others, neuroticism, and agreeableness.

The success of any organization mainly depends on physical and psychological participation of human workforce. The human performance is greatly depends on psychological capital which includes developable, controllable, and measureable application of psychological capital. Cavus and Gokcen [10] defined the psychological capital and their components and effects. Psychological capital has dimensions like self-reliance, self-efficacy, optimism, hope and resilience.

Li et al. [27] studied the relationship between occupational stress and job burnout with mediating role of psychological capital among Chinese bank employees. The outcomes indicated that psychological capital has the potential to overcome the negative effects of occupational stress on job burnout. Wang et al. [37] studied the association between work-family conflict and burnout with mediating role of psychological capital among Chinese doctors. The statistical outcomes confirmed that psychological capital was partially mediating the relationship of work-family conflicts and burnout.

Mohagheghi et al. [30] conducted a research study to find out the mediating role of job resources and psychological capital in job burnout and job demands. The findings depicted that psychological capital played a mediating role with four constructs self-efficacy, optimism, resilience and hope. Yim et al. [38] evaluated the association between occupational stress and turnover intention with mediating role of psychological capital among nurses. The outcomes revealed that all study variables have positively correlated and psychological capital play a mediating role. Shang Guan et al. [35] conducted a cross-sectional study to investigate the association between occupational stress and job satisfaction with mediating role of psychological capital. The outcomes indicated that psychological capital played a partially mediating role between job stress and job satisfaction.

\section{Research gap}

The behavior play a significant role toward the social and psychological well-being of organization employees. The motivated leadership is a key factor in maintaining and attracting employees in organization [15]. The previous research work depicted that leader narcissism affect the ethical behavior of subordinate and they harm or intention to harm the organization assets $[15,25]$. Munir et al. [31] described that nurses face violence behavior from their horizontal staff and their intention to quit the job and harm the organization. More than $80 \%$ nurses in Pakistan facing negative behavior due to negative image of nursing profession in Pakistan. The current research study was based on Erkutlu and Chafra [15] research study "Leader's narcissism and organizational cynicism in healthcare organization". The healthcare sector in Pakistan has in their transformational phases, very limited research work was done to highlight the narcissistic personality disorder (NPD) on cognitive organization cynicism (COC). This research work highlights their relationship with mediating role of psychological capital (PS). Erkutlu and Chafra [15] recommended to conduct further research in other developing economies with more representative mix of sample population. In past research study stressor-strain prospective as a mediating factor to influence narcissism and organization cynicism relationship.

The current research work is the designated first study to evaluate the relationship between narcissistic personality disorder (NPD) and cognitive organization cynicism (COC) with mediating role of psychological capital (PS) in Pakistan.

\section{Problem statement}

In the recent study of Jafree [22] portray that nurses in Pakistan have to face attitude problems. Due to this they have serious physical, mental, and social problems. In healthcare sector, the quality of care is based on 
motivated employees. At the start of their career in public healthcare entities, employees believe that their superior and colleague will well-come them with open mind. But soon they realized that these entities are run by few main players and rest of the employees are just observer. Then they become de-motivated and show unethical behavior at individual and organization level. The main players demoralized the motivated employees and attached his/ her name with other works. In this situation, the frustration level in motivated personnel rises and they harm the vision and mission of the organizations. The person depicted such type of behavior has a personality disorder termed as Narcissism. These personnel think that system are responsible for such kind of hostile working atmosphere this situation is called cynicism in organization.

In Pakistan, the quality of patients care is badly suffered due to unethical behavior of frontline staff. In the presence of narcissism behavior, the organization has cynicism atmosphere. The empirical results from past studies depicted that narcissistic workforce/employees have low level of integrity. Furthermore, narcissism leads to low level of ethical and moral responsiveness. In this way, the healthcare workforce prefer their own working during their working hours instead to achieve organization goals and vision.

\section{Research objectives}

1. To analysis the narcissism personality disorder factors that impact the cognitive organization cynicism.

2. To analysis the role of narcissism personality disorder and psychological capital.

3. To assess the Narcissistic Personality Disorder on Cognitive Organizational Cynicism through/via Psychological Capital.

\section{Research questions}

1. Has the narcissism personality disorder significant negative impact on cognitive organization cynicism?

2. What is the impact of narcissism personality disorder on psychological capital?

3. What is the role of psychological capital to intervene the association between narcissism personality disorder and cognitive organization cynicism?

\section{Literature review}

\section{Narcissism personality disorder}

In the research work of Grijalva and Harms [18], narcissism significantly correlates with counterproductive work behavior and leadership effectiveness. They propose dominance complementarily model to examine the narcissistic leader's interaction with their followers. This study proposes four management areas: corporate social responsibility, entrepreneurship, negotiation, and international management that may gain benefits from included narcissism in organizational operations. In another study of Grijalva and Newman [19] depicted that counterproductive work behavior was predicted by narcissism after controlling the effect of big five personality traits and collectivist culture. They propose two new moderators narcissism facets (Entitlement) positively linked with counterproductive work behavior and authority negatively correlate with counterproductive work behavior.

The widely used term to measure narcissism is Narcissistic Personality Inventory (NPI). In the study of Ackerman et al. [1], NPI was measured from triangle factors; grandiose exhibitionism, entitlement and authority and NPI was divided into adaptive or normal narcissism and maladaptive narcissism. The adaptive or normal narcissism aspects are extraversion, self-esteem, goal persistence and social potency. The maladaptive has further divided into grandiose exhibitionism and entitlement. Forsyth et al. [17] conducted a meta-analysis to evaluate the tri-dark personality traits; narcissism, Machiavellianism and psychopathy on job performance and counterproductive work behavior. The outcomes confirmed that tri-dark traits significantly associated with increase counterproductive work behavior, and job performance become low in the presence of Machiavellianism and psychopathy factors. These associations were moderately affected by authority and cultures. Carlson and Gjerde [9] conducted a longitudinal study to examine the association between pre-school personality antecedents of narcissism during emergent adulthood and adolescence. The results illustrated that from age 14-18, narcissism increase significantly and slightly declined from 18 to 23 years of age. Erkutlu and Chafra [15] examined the impact of leader narcissism on subordinate embeddedness with moderating role of behavioral integrity and moral attentiveness. The empirical results confirmed that leader's narcissism negatively linked with subordinate embeddedness. Furthermore, such association was weaker when behavioral integrity and moral attentiveness were high and vice versa. In another study, Erkutlu and Chafra [14] examine the moderating role of narcissistic personality in measuring the association between leaders behavioral and workplace ostracism.

\section{Organizational cynicism}

The extremely negative behavior and attitudes articulated by so many personnel toward their institution is still debating topic in the eyes of many researchers. The 
concept of cynicism was originated in ancient Greece. Dean et al. [13] analysis the available literature on cynicism and conceptualization new, multidimensional and comprehensive definition of organization cynicism as follows'

\section{Organizational cynicism is a negative attitude toward one's employing organization, comprising three dimensions: (1) a belief that the organization lacks integrity; (2) negative affect toward the organi- zation; and (3) tendencies to disparaging and criti- cal behaviors toward the organization that are con- sistent with these beliefs and affect.}

Munir et al. [31] study the mediating role of organizational cynicism in determining the association between horizontal violence and turnover intention of nurses working in public hospital in Punjab, Pakistan. The statistical results indicated that the direct effect of horizontal violence on turnover intention was significant but with mediating role of organizational cynicism was insignificant and organizational cynicism has not mediating role in determining the association between horizontal violence and turnover intention in nursing profession. Polatcan and Titrek [32] examined the association of school principal leadership behavior (indulgence and construction) on teachers attitudes toward different level of organizational cynicism (cognitive, behavioral, and emotional). The outcomes illustrated that there was significant negative association between school principal leadership behavior and teachers attitudes toward different level of organization cynicism. The medium negative level of correlation found between indulgence and construction dimensions of leadership and organizational cynicism level with ordering from highest to lowest was; cognitive, behavioral and emotional.

Aslam et al. [3] explored the causes of organizational cynicism against change initiative in Pakistan. The dimension of organizational cynicism with change were behavioral resistance, cognitive resistance, and dispositional resistance. The study concluded that to implement change effectively and efficiently, cynicism factors must be removed at organizational and management level. The effective participation of employees in decision making process, positive information relating to employee job security, wage rewards, and promotional criteria can effectively reduce the cynicism in the organization. Kaygin et al. [25] determined the association between organizational cynicism (cognitive, affective and behavioral) and organization commitment (organizational, emotional, continuance and normative). The results illustrated that significant and positive association found between organization cynicism and organizational commitments at medium level. The association between sub-dimensions of organization cynicism and commitments was significant at low level.

\section{Psychological capital}

The concepts, components and effect of psychological capital in management sciences was well explained in the article of Cavus and Gokcen [10]. The psychological capital has four constructs; confidence/self-efficacy, hope, optimism and resiliency. Furthermore, psychological capital briefly touches the different areas of individual behaviors like job satisfaction, performance and motivation. In the work of Batool [5] examining the effect of different dimensions of psychological capital on employee engagement. Psychological capital has four positive dimensions: hope, optimism, resiliency, and self-efficacy.

Cross-sectional study of Shang Guan et al. [35] examined the mediating role of psychological capital in determining the association between occupational stress and job satisfaction in China. The statistical results confirmed that psychological capital was partially mediating between the association of occupational stress and job satisfaction. The direct association between occupational stress and job satisfaction was significantly negative, whereas psychological capital positively correlate with job satisfaction. Lorenz et al. [28] developed a new measure of psychological capital: Compound PsyCap Scale (CPC-12). They measure positive and negative psychological capital with other constructs like job satisfaction, satisfaction with life, subjective well-being, perceived social support, meaning of work, engagement, gratitude and personality. The outcomes confirmed that proposed measure CPC12 was statistically well with all four sub-scales of psychological capital.

Mohagheghi et al. [30] studied the association between job demands and job burnout with mediating role of job resources and psychological capital in Iran. The results confirmed that job demand was the important predictor of job burnout and mediating role of psychological capital and job resources were significant and consistent with past research work. Turgut and Agun [36] analysis the mediating role of psychological capital and employee voice in determining the relationship between organizational justice and organizational cynicism. The results depicted that negative association exist between organizational justice and organizational cynicism. But mediating role of psychological capital and employee voice was not found through regression analysis. Furthermore, regression analysis indicated that only procedural justice (organizational justice) dimension significantly impact 
on four sub-dimensions of psychological capital. Yim et al. [38] explored the association between occupational stress and turnover intention among nurses with mediating role of psychological capital. The results depicted that significant correlation exists among all study variables. The role psychological capital in the relationship between occupational stress and turnover intention was partial mediating.

\section{Relationship between narcissism personality disorder and organizational cynicism}

The available literature evident the importance of narcissism personality disorder in relation to workplace outcomes generally and cynicism and leadership particularly. Substantial evidence shows in the study of Erkutlu and Chafra [15] examine the impact of leader's narcissism on organizational cynicism with mediating role of psychological capital and moderating role of psychological strain in healthcare sector of Turkey. The results depicted that positive association exist between leader's narcissism and cynicism and psychological strain. Furthermore, psychological capital efficiently mediated the positive association between psychological strain and organization cynicism, and in another research study of Bell [6] "Cynicism and narcissism: making the good life". This study distinguished the different types of narcissism and measured cynicism both at local and global level. This study marked both cynicism and narcissism was marked by interpersonal difficulties and may inhibit gratitude.

Forsyth et al. [17] grouped narcissism, psychopathy, and Machiavellianism as dark triad and significantly impact on job performance and counterproductive work behavior. This association were moderated by authority and culture. In all three dark triad, the strongest individual triad was narcissism. The strength of association between narcissism and counterproductive work behavior was not buffered in the presence of authority construct, but such relationship became weaker when culture construct became increased. From the comparative study of Malik and Khan [29], it is evident that narcissistic leader's behavior present in public and private organizations in Pakistan. The boss narcissistic behavior was categorized into self-absorbed, paranoia, self-promoting, and intellectual inhibition and secretive and vague. The empirical results described that when boss's narcissism behavior at workplace increase then lack of subordinates/ employees commitment, lack of motivation, deterioration of employees behavior and attitude and lack of ownership were also amplify.

In the thematic analysis by Braun [7], study of the leader narcissism and their outcomes at three different but inter-related levels: leader-follower dyads, organizations, and teams is done. The outcomes suggested that at leader-follower dyads level, leader's narcissism positive impact on follower's career and negative effect on follower's emotions, citizenship and counter productivity. Furthermore, narcissism defines leader's attitudes (humility) and followers responses (enactment). In teams setting, narcissist persons were not as bad leaders, but perceptions may be deteriorating over time. Moreover, the association between performance and leaders narcissism became negative, but in certain conditions, leader's narcissism can fuel individual performance. At organization level, narcissistic CEOs were stronger in-group orientation but lack of clear objectives and goals. Furthermore, CEO's narcissism will reshape the personnel decisions with lower restrictions.

Aslam et al. [3] examined the impact of organizational cynicism on personality traits, job outcomes and organizational contextual factors. The subscale of organizational cynicism was behavioral resistance, cognitive resistance, and dispositional resistance. Behavioral resistance dimension moderates the relationship among employee intention, organizational contextual factors, and dispositional resistance. Cognitive resistance has no association with information to change, continuance commitment and trust in management. In another study, Polatcan and Titrek [32] significantly examined the association between school principals leadership behavior and organizational cynicism attitudes of employees. The association between leadership behavior (construction and empathizing) and organizational cynicism was negative. The ordering of organization cynicism in this study was cognitive, behavioral, and affective. The statistical results depicted that demographic did not affect the association between leaders behavior and organization cynicism. The association between leader behavior and organization cynicism was negative, but teachers perceptions, cognitive, and behavioral level were at highest and in emotional at low.

\section{Mediating role of psychological capital between narcissism personality disorder and organizational cynicism}

No doubt, personnel positive behavior at their workplace will improve relationship and thoughts either at group or individual level. It also improve personal capacity to realize their potential and to perform efficiently. Yim et al. [38] evaluated the mediating role of psychological capital to access the association between occupational stress and nurses turnover intention in South Korea. There was a negative but significant correlation exist between occupational stress and psychological capital. The association between psychological capital and nurse's 
turnover intention was also negative. The mediating role of psychological capital was examined through Baron and Kenny method. The outcome depicted that psychological capital played a partial mediating role in the association between occupational stress and nurse's turnover intention.

In another study, Li et al. [27] examined the mediating role of psychological capital to access the relationship between occupational stress (extrinsic effort, rewards and over-commitments) and job burnout (emotional exhaustion, depersonalization and personal accomplishment) of bank employees in China. The mediating role of psychological capital was explored through asymptotic and resampling strategies. The statistical results depicted that the mediating role of psychological capital was affected by gender difference. In female bank employees, psychological capital partially mediated the relationship between occupational stress and job burnout, whereas in male bank employees, psychological capital fully mediated the association between occupational stress and job burnout.

Turgut and Agun [36] examined the association between organizational justice and organizational cynicism with mediating role of psychological capital and employee voice. The findings illustrated that negative and significant association exist between organizational justice and organization cynicism and also with psychological capital. A three-step regression model was applied to measure the mediating role of psychological capital suggested by Baron and Kenny [4]. No mediating role of psychological capital was found in the relationship between organizational justice and organization cynicism. Study of Mohagheghi et al. [30] examined the association between job demands and job burnout with the mediating role of job resources and psychological capital. The structural equation model and Sobel test were applied to measure the model fit test and mediation. The outcomes revealed significant association exist between job demands and job burnout. The mediating role of psychological capital in the association between job demands and job burnout was confirmed through Sobel test.

Wang et al. [37] evaluated the mediating role of psychological capital in studying the association between work-family conflict (work interfering family conflict and family interfering work conflict) and burnout (cynicism, professional efficacy and emotional exhaustion) among doctors in China. The mediation role of psychological capital was affected by gender characteristic (male and female). The outcomes depicted that work-family conflicts positively related with burnout. The Sobel test was applied to measure the mediation affect. In male doctors, psychological capital partially mediate the relationship between work interfering family conflict and professional efficacy. In female doctors, psychological capital partially mediate the relationship between family interfering work conflict and cynicism and emotional exhaustion.

\section{Supported theories}

\section{Social exchange theory}

In social exchange theory, two or more persons voluntarily exchange and provide resources that each perceives as rewards. In evaluating the client and nurse interaction, theory of social exchange has been identified as a prospective framework [8]. Redmond [33] visualizes the social exchange theory;

Exchange $=$ trade something at cost to attain some valued reward.

Rewards-costs $=$ negative or positive outcomes (profits or loss).

Inequity $=$ rewards $<$ cost or your rewards $>$ my rewards.

Esmaeilzadeh et al. [16] evaluate the social exchange theory for the adoption of clinical IT in healthcare sector. The healthcare professional behavior was mainly depends on organizational context and well explained with social exchange theory. Redmond [33] explained the different elements of social exchange theory; rewards and value of reward, social reward, costs, profits, equity and distributive justice and social exchange. Holthausen [20] review the social exchange theory and its contribution in solving purchaser's decision making issues. The results depicted that social exchange theory improves the two-way relationship (buyer-supplier) and enhances the performance of the organization. Byrd [8] applied social exchange theory as a framework for client-nurse interaction during public health nursing maternal-child home visits. The outcomes depicted that social exchange theory was useful in classifying and specifying resources, understanding nursing strategies and explain the client-nurses interaction phenomena. In the study of Erkutlu and Chafra [15], the phenomenon of leader narcissism reshaping the follower behavior was explained with social exchange theory. Forsyth et al. [17] conducted a meta-analysis to evaluate the impact of dark triad and work behavior from social exchange perspective. In another study, Munir et al. [31] applied social exchange theory to explain the association among horizontal violence, organizational cynicism and turnover intention in nursing staff in public healthcare setting of Sindh, Pakistan. 


\section{Theory of well-being}

Theory of well-being covers the broad range of personal, institutional, global and cultural dimensions of life. In the book of Seligman [34], there were described many potential factors of well-being: Positive emotions, Engagement, Relationship, Measuring and Achievement (PERMA). These dimensions include hedonic and eudemonic aspects of human life. This theory has also unique elements like achievement and engagement that were not commonly discussed in other well-being theories [12]. In their study, Adler and Seligman [2] describe the use of well-being theory, measurement and recommendations. The measurement of well-being was categorized into subjective, eudemonic, beyond survey and national and international well-being. The following table describing the core and additional features of hedonic and eudemonic well-being (Table 1).
Youssef-Morgan and Luthans [39] presented a conceptual framework that psychological capital can promote well-being at individual and workplace level. Psychological capital was categorized into work, relationship, and health psychological capital, and all these factors significantly affect overall well-being of employee and organizations.

In the current study, researcher applied Seligman [34] theory of well-being, which has five interconnected dimensions; Positive emotions, Engagement, Relationship, Measuring and Achievement or PERMA. This theory explicitly explains the living a purposeful life (eudemonic) and living a life rich in pleasure and joy (hedonic) components (Fig. 1).

\section{Research model}

See Fig. 2.

Table 1 Hedonic and eudemonic well-being. Source: Adler and Seligman [2]

\begin{tabular}{ll}
\hline Core features & Additional features \\
\hline Positive emotions & Self-esteem \\
Engagement & Optimism \\
Interest & Resilience \\
Meaning & Vitality \\
Purpose & Self-determination \\
& Positive relationships \\
\hline
\end{tabular}

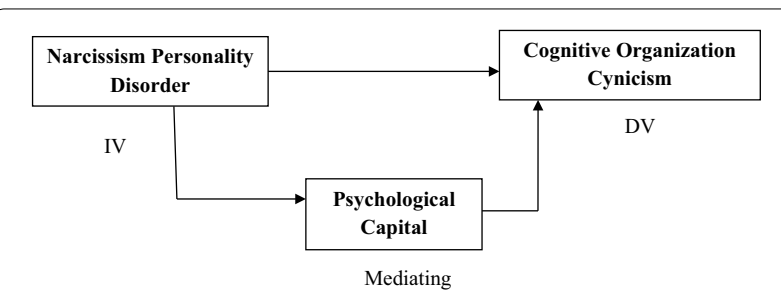

Fig. 2 Research model

\section{BUILDING BLocKS OF THE GOOd LIFE}

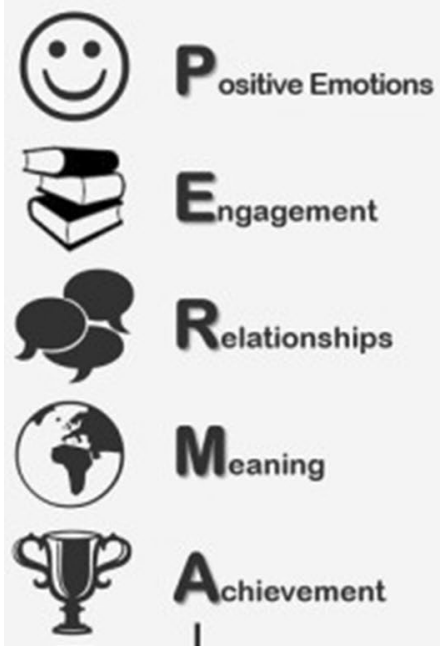

Experiencing Positive Emotions Such As Happiness, Satisfaction, SelfRegard, Serenity, \& Cheerfulness On A Regular Basis

having interests \& Pursuits That Deeply Captivate Us, Resulting In The Regular EXPERIEnce Of Flow \& Personal Growth

Experiencing Affection, Friendship, And Love (In Both Directions) With OTHER (HUMAN) BEINGS IN DIFFERENT CONTEXTS (FAMILY, LEISURE, WORK)

BELEVING In \& Working TOWARDS SOMETHINg THAT TRANSCENDS OURSELVES \& OUR LifETIMES (BE IT IN THE SECULAR OR SPIRITUAL Domain)

Experiencing A Sense Of ACCOMpushment (Being A Success Story) On A Regular Basis, Be it in the Occupational domain Or In Our Private lives

Fig. 1 PERMA theory of well-being by Seligman [34] 


\section{Hypotheses generation}

$\mathrm{H}_{1}=$ narcissism personality disorder has an impact on cognitive organization cynicism.

$\mathrm{H}_{2}=$ narcissism personality disorder has an association with psychological capital.

$\mathrm{H}_{3}=$ psychological capital has significant association with cognitive organizational cynicism.

$\mathrm{H}_{4}=$ psychological capital mediate the relationship between narcissism personality disorder and cognitive organizational cynicism.

\section{Methods}

\section{Research design}

The prime objective of this study is to analysis the impact of narcissism personality disorder on cognitive organizational cynicism with mediating role of psychological capital in nurses performing their job in primary healthcare hospitals of Okara, Pakpatten and Sahiwal.

\section{Research philosophy}

In the current study, researcher developed the constructs from existing theories, generate hypotheses, adopt strategies for data collection and perform test to prove the proposed hypothesis. Therefore, the research philosophy adopted in this study is positivist.

\section{Research choice}

The current nature of study was based on existing theory to analysis the significant association between NPD and $\mathrm{COC}$ with mediating role of psychological capital. The research choice is classified into qualitative and quantitative. When naturally occurring events and facts are gathered, the qualitative research was used. In contract, quantitative research choice was applied when social responses and facts were collected. In this research, human behavior responses were collected through adapted questionnaires, so research choice is quantitative.

\section{Research nature}

The nature of current study is causal which explains the cause and effect relationship among study variables $[15$, 31]. The research data was gathered in one time setting, i.e., from January 2018 to February 2018 from nurses performing their duty in primary healthcare units in three districts of Punjab (Okara, Pakpatten and Sahiwal) at their place of working during official timing.

\section{Sample and size}

The nursing carder is the unit of analysis in this research study, the researcher know the population size, i.e., 1250 of nurses performing duties at DHQ's, THQ's and RHC's in division Sahiwal, Punjab. The sample was calculated with the method of Krejcie and Morgan [26] of known population. The final sample size for this study was 294 at 0.05 margin of error and 95 per cent confidence level. In this research work, researcher used simple random sampling technique to select the sample from sampling frame using computer-generated list of nurses. The list of nursing staff is generated from website or spreadsheet, to ensure the selection of every item the repeated person will be ignored and replaced. A complete list of population is stored in computer and possible to select sample of randomly selected cases.

\section{Data analysis \\ Statistical test and results \\ Reliability}

\begin{tabular}{|c|c|c|c|c|}
\hline \multicolumn{2}{|c|}{ Variable types } & \multirow{2}{*}{$\begin{array}{c}\text { Scale name } \\
\begin{array}{c}\text { Leadership/ } \\
\text { authority }\end{array}\end{array}$} & \multirow{2}{*}{$\begin{array}{l}\text { No of items } \\
6\end{array}$} & \multirow{2}{*}{$\begin{array}{l}\begin{array}{l}\text { Cronbach's } \\
\text { alpha }\end{array} \\
0.812\end{array}$} \\
\hline $\begin{array}{l}\text { Independ- } \\
\text { ent vari- } \\
\text { ables }\end{array}$ & $\begin{array}{l}\text { Narcissism } \\
\text { person- } \\
\text { ality } \\
\text { disorder } \\
\text { (NPD) }\end{array}$ & & & \\
\hline & & $\begin{array}{l}\text { Grandiose } \\
\text { exhibi- } \\
\text { tionism }\end{array}$ & 6 & 0.806 \\
\hline & & $\begin{array}{c}\text { Entitlement/ } \\
\text { exploita- } \\
\text { tiveness }\end{array}$ & 5 & 0.853 \\
\hline \multirow[t]{4}{*}{$\begin{array}{l}\text { Mediating } \\
\text { variable }\end{array}$} & $\begin{array}{l}\text { Psychologi- } \\
\text { cal capital }\end{array}$ & Self-efficacy & 4 & 0.768 \\
\hline & & Hope & 4 & 0.882 \\
\hline & & Optimism & 4 & 0.804 \\
\hline & & Resilience & 4 & 0.818 \\
\hline $\begin{array}{l}\text { Dependent } \\
\text { variable }\end{array}$ & & $\begin{array}{l}\text { Cognitive } \\
\text { organi- } \\
\text { zational } \\
\text { cynicism } \\
\text { (COC) }\end{array}$ & 5 & 0.845 \\
\hline
\end{tabular}

Krejcie and Morgan [26] describe the term Cronbach alpha is used to measure the internal consistency of study scale or variables. Internal consistency means that all items in the questionnaires measure the same constructs or concepts of the study. Furthermore, it measures the measurement/variance/random errors in a test. The Cronbach alpha is expressed in numerical values ranging 
from 0 to 1 . The acceptable value of Cronbach alpha from 0.70 to 0.95 .

Narcissism Personality Disorder (NPD) has three subconstructs; leadership, grandiose exhibitionism and entitlement and the value of Cronbach alpha are 0.855, 0.881 and 0.808 respectively. The cognitive Organizational Cynicism $(\mathrm{COC})$ variable has five items with 0.884 reliability. The mediating variable Psychological Capital (PsyCap) has four sub-constructs; self-efficacy, hope, optimism and resilience and their Cronbach alpha values are $0.859,0.769,0.725$, and 0.774 , respectively. All the study variables have alpha values are within the range.

\section{Validity and principal component analysis}

\begin{tabular}{lll}
\hline KMO and Bartlett's test & & \\
\hline Kaiser-Meyer-Olkin measure of sampling adequacy. & .823 \\
\hline Bartlett's Test of Sphericity & Approx. & 3765.643 \\
& Chi- & \\
square & \\
Df & 28 \\
& Sig. & .000 \\
\hline
\end{tabular}

The validity test has two subtests: Kaiser-Meyer-Olkin (KMO) and Bartlett's test of Sphericity. KMO measures the sampling adequacy and Bartlett's test measure that all off-diagonal terms have zero value and all diagonal terms have one value. In other words, Bartlett's test the hypotheses that correlation matrix has identity matrix. The KMO value above 0.5 is considered acceptable for further analysis and Bartlett's test has significance value $<0.05$ or less.

In the above table the KMO value is 0.778 which significance level 0.000 , which means researcher can continue further analysis.

\begin{tabular}{lll}
\hline & Initial & Extraction \\
\hline Communalities & & \\
NPD_LA & 1.000 & .769 \\
NPD_GE & 1.000 & .572 \\
NPD_EE & 1.000 & .952
\end{tabular}

\begin{tabular}{lll}
\hline & Initial & Extraction \\
\hline PSY_SE & 1.000 & .918 \\
PSY_H & 1.000 & .966 \\
PSY_OP & 1.000 & .950 \\
PSY_RE & 1.000 & .937 \\
COC & 1.000 & .982 \\
\hline
\end{tabular}

Extraction method: principal component analysis

The purpose of communalities in factor analysis is to indicate the common variance shared by factors with given variables. It is based on initial assumption that before extraction all variances are common; therefore, the initial column values of all variables are 1 . The extraction column depicted the common variance in the data set. The extraction values are reliable when extracted communalities are at least more than 0.70 and less than 30 variables or extracted communalities values equal or above 0.60 and the sample size is above 250 cases. In the above table, all the values of variables are above 0.60 expect NPD_GE which 0.572 , that is close to 0.60 . The above communalities table, it depicted that $76.9 \%$ of the variance associated with NPD_LA is common, $57 \%$ common variance of NPD_GE, 95\% of common variance of NPD_EE, 91.8\% of Psy_SE, 96.6\% of Psy_H, 95\% of Psy_ OP, $93.7 \%$ of Psy_RE and COC has common variance $98.2 \%$.

\begin{tabular}{|c|c|c|c|c|c|c|}
\hline \multirow[t]{2}{*}{ Component } & \multicolumn{3}{|c|}{ Initial eigenvalues } & \multicolumn{3}{|c|}{$\begin{array}{l}\text { Extraction sums } \\
\text { of squared loadings }\end{array}$} \\
\hline & Total & $\begin{array}{l}\% \text { of } \\
\text { Variance }\end{array}$ & $\begin{array}{l}\text { Cumulative } \\
\text { e (\%) }\end{array}$ & eTotal & $\begin{array}{l}\% \text { of } \\
\text { variance }\end{array}$ & $\begin{array}{l}\text { Cumulative } \\
\text { (\%) }\end{array}$ \\
\hline \multicolumn{7}{|c|}{ Total variance explained } \\
\hline 1 & 5.635 & 70.433 & 70.433 & 5.635 & 70.433 & 70.433 \\
\hline 2 & 1.412 & 17.647 & 88.080 & 1.412 & 17.647 & 88.080 \\
\hline 3 & .554 & 6.931 & 95.010 & & & \\
\hline 4 & .270 & 3.370 & 98.381 & & & \\
\hline 5 & .081 & 1.010 & 99.391 & & & \\
\hline 6 & .026 & .330 & 99.721 & & & \\
\hline 7 & .015 & .188 & 99.909 & & & \\
\hline 8 & .007 & .091 & 100.000 & & & \\
\hline
\end{tabular}

Extraction method: principal component analysis 


\section{Conformity factory analysis}

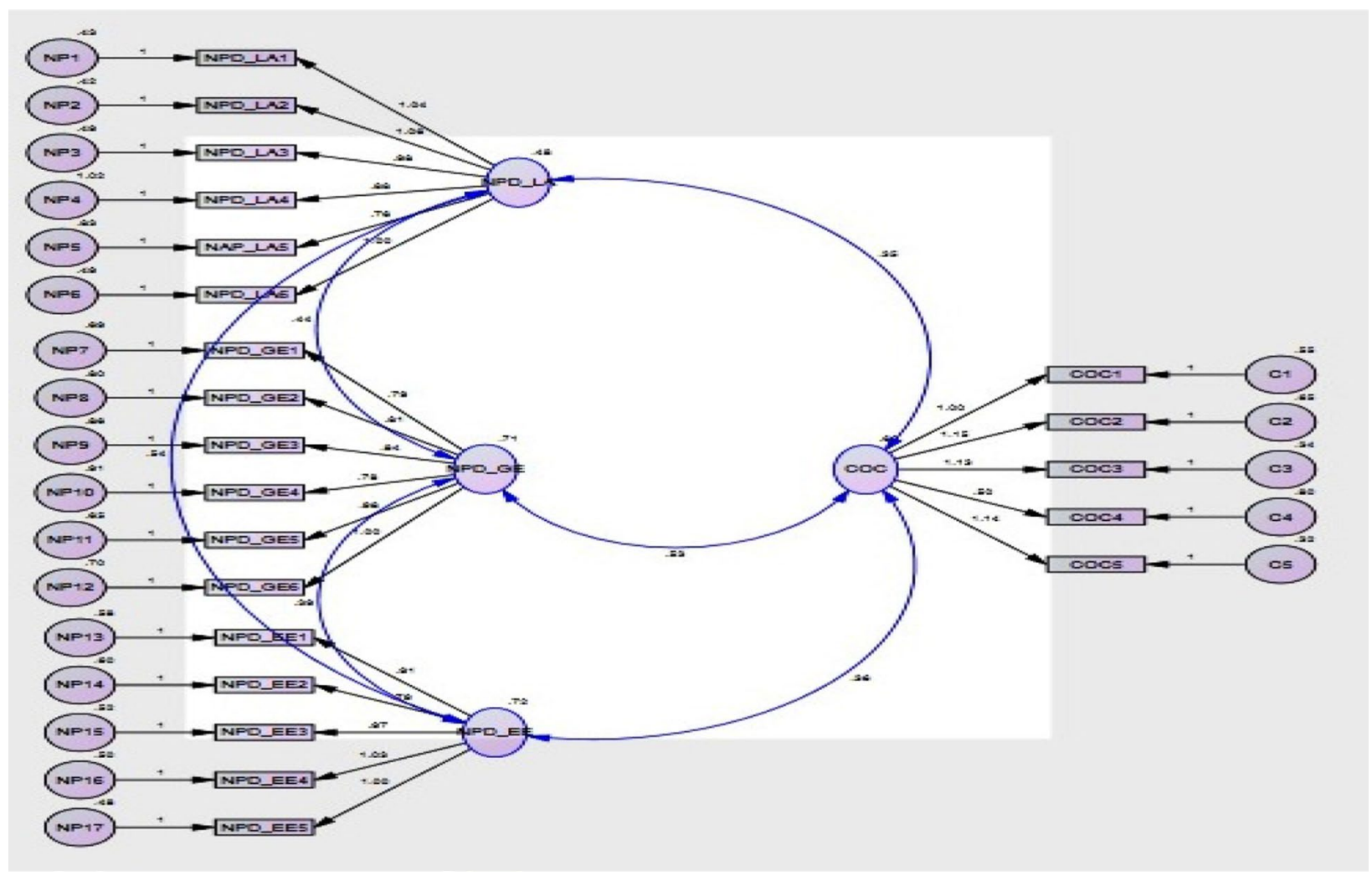

The above SPSS output table depicted the initial eigenvalues before extraction and after extraction. Before extraction, there are eight component in the data set. The eigenvalues associated with each factor represent the variance explained by the particular liner component and SPSS displayed the eigenvalues in terms of percentage. The first factor has eigenvalue $70.433 \%$ which means that it explain $70 \%$ of the total variance. The second factor explain $17.647 \%$ of total variance. The first two factors explained large amount of variance but the subsequent factors explain small amount of variance. The SPSS further extract only those values that have initial eigenvalues greater than 1 . Both factors explain total variance $70.433 \%$ and $17.647 \%$ respectively.

\section{Descriptive statistics}

\section{$N$ Minimum Maximum Mean SD}

\begin{tabular}{llllll}
\hline Descriptive statistics & & & & & \\
NPD_LA & 254 & 1.00 & 5.00 & 4.0899 & .81536 \\
NPD_GE & 254 & 1.00 & 5.00 & 4.0774 & .86248 \\
NPD_EE & 254 & 1.00 & 5.00 & 4.1063 & .84496 \\
PSY_SE & 254 & 1.00 & 5.00 & 4.0197 & .88555
\end{tabular}

\begin{tabular}{llllll}
\hline & $\boldsymbol{N}$ & Minimum & Maximum & Mean & SD \\
\hline PSY_H & 254 & 1.00 & 5.00 & 3.6299 & .90609 \\
PSY_OPT & 254 & 1.00 & 5.00 & 3.8533 & .81391 \\
PSY_RE & 254 & 1.00 & 5.00 & 3.9803 & .84149 \\
COC & 254 & 1.00 & 5.00 & 3.7630 & .97416 \\
Valid N (listwise) & 254 & & & & \\
\hline
\end{tabular}

The descriptive statistics were further divided into measure of central tendency (mean) and measures of variability (standard deviation). The mean used to measure the center of gravity of distributions. In the above table, NPD has mean value above four and PsyCap and organizational cynicism have above three.

\section{Demographic}

In this research work, questionnaire was divided into two section demographic and rating questions. The demographic section has constructs: age, level of education, Job tenure, and department.

\begin{tabular}{lllll}
\hline Age & Frequency & Percent & Valid percent & $\begin{array}{l}\text { Cumulative } \\
\text { percent }\end{array}$ \\
\hline $\begin{array}{l}\text { Valid } \\
22 \text { and less }\end{array}$ & 40 & 16.1 & 16.1 & 16.1
\end{tabular}




\begin{tabular}{llrlc}
\hline Age & Frequency & Percent & Valid percent & $\begin{array}{l}\text { Cumulative } \\
\text { percent }\end{array}$ \\
\hline $23-25$ & 37 & 14.5 & 14.5 & 30.6 \\
$26-30$ & 53 & 20.8 & 20.8 & 51.4 \\
$31-35$ & 47 & 18.4 & 18.4 & 69.8 \\
$36-40$ & 59 & 23.1 & 23.1 & 92.9 \\
41 and & 18 & 7.1 & 7.1 & 100.0 \\
$\quad$ above & & & & \\
Total & 254 & 100.0 & 100.0 & \\
\hline
\end{tabular}

There were 41 responses received from nurses having age 22 and less with $16.1 \%$.. Nurses from 23 to 25 agegroup have 37 frequency with $14.5 \%$. The second participative age-group were $26-30$ with 53 frequency and $20.8 \%$. The moderate age-group was $31-35$ having 47 frequency and $18.4 \%$. The most participative age-group was $36-40$ with 59 frequency and $23.1 \%$. The least active agegroup was 41 and above with 18 frequency and $7.1 \%$.

\begin{tabular}{lrrrr}
\hline Department & Frequency & Percent & Valid percent & $\begin{array}{l}\text { Cumulative } \\
\text { percent }\end{array}$ \\
\hline Valid & & & & \\
Emergency & 70 & 27.5 & 27.5 & 27.5 \\
Indoor & 140 & 55.3 & 55.3 & 82.7 \\
OPD & 44 & 17.3 & 17.3 & 100.0 \\
Total & 254 & 100.0 & 100.0 & \\
\hline
\end{tabular}

Most of primary healthcare facilities have three major department: emergency, indoor and OPD. Most of nurses performed their duties in indoor section of the hospitals with 140 frequency and $55.3 \%$. The least participants belong to OPD department with 44 in total and $17.3 \%$. The nurses performing their duty in emergency were 70 in total with $27.5 \%$.

\section{Correlation analysis}

\begin{tabular}{|c|c|c|c|c|c|c|c|c|}
\hline Correlations $^{a}$ & NPD_LA & NPD_GE & NPD_EE & PSY_SE & PSY_H & PSY_OPT & PSY_RE & $\mathrm{COC}$ \\
\hline \multicolumn{9}{|l|}{ NPD_LA } \\
\hline Pearson correlation & 1 & & & & & & & \\
\hline \multicolumn{9}{|l|}{ Sig. (2-tailed) } \\
\hline \multicolumn{9}{|l|}{ NPD_GE } \\
\hline Pearson correlation & $.809^{* *}$ & 1 & & & & & & \\
\hline Sig. (2-tailed) & .000 & & & & & & & \\
\hline \multicolumn{9}{|l|}{ NPD_EE } \\
\hline Pearson correlation & $.933^{* *}$ & $.766^{* *}$ & 1 & & & & & \\
\hline Sig. (2-tailed) & .000 & .000 & & & & & & \\
\hline \multicolumn{9}{|l|}{ PSY_SE } \\
\hline Pearson correlation & $.747^{* *}$ & $.802^{* *}$ & $.718^{* *}$ & 1 & & & & \\
\hline Sig. (2-tailed) & .000 & .000 & .000 & & & & & \\
\hline \multicolumn{9}{|l|}{ PSY_H } \\
\hline Pearson correlation & $.539^{* *}$ & $.403^{* *}$ & $.559^{* *}$ & $.395^{* *}$ & 1 & & & \\
\hline Sig. (2-tailed) & .000 & .000 & .000 & .000 & & & & \\
\hline \multicolumn{9}{|l|}{ PSY_OPT } \\
\hline Pearson correlation & $.736^{* *}$ & $.751^{* *}$ & $.708^{* *}$ & $.923^{* *}$ & $.610^{* *}$ & 1 & & \\
\hline Sig. (2-tailed) & .000 & .000 & .000 & .000 & .000 & & & \\
\hline \multicolumn{9}{|l|}{ PSY_RE } \\
\hline Pearson correlation & $.718^{* *}$ & $.685^{* *}$ & $.694^{* *}$ & $.787^{* *}$ & $.563^{* *}$ & $.760^{* *}$ & 1 & \\
\hline Sig. (2-tailed) & .000 & .000 & .000 & .000 & .000 & .000 & & \\
\hline \multicolumn{9}{|l|}{$\operatorname{coc}$} \\
\hline Pearson correlation & $.505^{* *}$ & $.450^{* *}$ & $.474^{* *}$ & $.426^{* *}$ & $.615^{* *}$ & $.491^{* *}$ & $.811^{* *}$ & 1 \\
\hline Sig. (2-tailed) & .000 & .000 & .000 & .000 & .000 & .000 & .000 & \\
\hline
\end{tabular}

${ }^{a}$ Listwise $N=254$

"*Correlation is significant at the 0.01 level (2-tailed)The correlation test measured the association between two or more variables. The correlation is categorized into positive, negative and no correlation. The most commonly used method to measure the correlation between variables is Pearson correlation. Johannesson and Perjons [23] explained the value of correlation ranging from +1 to -1 , the value +1 indicate strong positive correlation, -1 value depicted that strong negative correlation between variables and zero (0) indicated that no correlation. 
The above correlation table depicted the relationship among NPD constructs, COC and PsyCap constructs. The COC have moderate association with NPD_LA, NPD_GE, NPD_EE, PSY_SE and PSY_OPT having values $0.505,0.450,0.474,0.426$, and 0.491 respectively. The COC has strong association with PSY_H having value 0.615 and very strong correlation with PSY_RE having 0.815 .

Mediation analysis through Baron and Kenny's [4] Combine effect of narcissism personality disorder (NPD_LA, NPD_GE, NPD_EE) on cognitive organizational cynicism (COC) with mediating role of all sub-constructs of psychological capital (PSY_SE, PSY_H, PSY_OPT, PSY_RE) variable. The $p$ value of first equation is significant $<0.05$. In second equation, NPD as independent and PsyCap. As dependent variables. The second equation has also significant $p$ value which is less than 0.05 . In the third equation, NPD and PsyCap. Became as independent variables and $\mathrm{COC}$ as dependent variable. The researcher applied multiple regression to find the mediation impact of Psychological capital. The ANOVA table has significant $\mathrm{p}$ value, but the coefficient table has insignificant $p$ value of NPD (0.347) but significant $p$ value of PsyCap.

Hence, according to Baron and Kenny [4] mediation analysis when third equation has insignificant then there is partial mediation.

\begin{tabular}{|c|c|c|c|c|c|c|c|c|c|}
\hline & $\begin{array}{l}\text { Dependent } \\
\text { variable }\end{array}$ & $\begin{array}{l}\text { Independent } \\
\text { variable }\end{array}$ & $R^{2}$ & Adj. $R^{2}$ & $F$ & $p$ & $\beta$ & $t$ & $p$ \\
\hline 1st equation & $\mathrm{COC}$ & NPD & 0.505 & 0.255 & 86.334 & 0.00 & 0.604 & 9.292 & 0.00 \\
\hline 2nd equation & PsyCap & NPD & 0.788 & 0.621 & 412.940 & 0.00 & 0.721 & 20.321 & 0.00 \\
\hline \multirow[t]{2}{*}{ 3rd equation } & $\mathrm{COC}$ & NPD & 0.677 & 0.458 & 105.982 & 0.00 & -0.071 & -0.942 & 0.347 \\
\hline & & PsyCap. & & & & & 0.099 & 9.686 & 0.00 \\
\hline
\end{tabular}

The researcher measure the combine impact of NPD and their sub-constructs on COC with all sub-constructs of PsyCap. Through Baron and Kenny's [4] mediation method through regression analysis. In the first equation, NPD as independent variable and COC as dependent
Individual NPD (leadership/authority, grandiose exhibitionism, entitlement/exploitativeness) impact on COC with mediating role of PsyCap

\begin{tabular}{|c|c|c|c|c|c|c|c|c|c|c|}
\hline & & $\begin{array}{l}\text { Dependent } \\
\text { variable }\end{array}$ & $\begin{array}{l}\text { Independent } \\
\text { variable }\end{array}$ & $R^{2}$ & Adj. $R^{2}$ & $F$ & $p$ & $\beta$ & $t$ & $p$ \\
\hline \multirow{4}{*}{$\begin{array}{l}\text { NPD_LA } \\
\text { COC } \\
\text { PsyCap }\end{array}$} & First equation & $\mathrm{COC}$ & NPD_LA & 0.505 & 0.255 & 86.334 & 0.00 & 0.604 & 9.292 & 0.00 \\
\hline & Second equation & PsyCap & NPD_LA & 0.788 & 0.621 & 412.940 & 0.00 & 0.721 & 20.321 & 0.00 \\
\hline & Third equation & $\mathrm{COC}$ & NPD_LA & 0.677 & 0.458 & 105.982 & 0.00 & -0.071 & -0.942 & 0.347 \\
\hline & & & PsyCap. & & & & & 0.731 & 9.686 & 0.00 \\
\hline \multirow{5}{*}{$\begin{array}{l}\text { NPD_GE } \\
\text { COC } \\
\text { PsyCap }\end{array}$} & First equation & $\operatorname{COC}$ & NPD_GE & 0.450 & 0.203 & 64.165 & 0.00 & 0.405 & 8.010 & 0.000 \\
\hline & Second equation & PsyCap & NPD_GE & 0.758 & 0.575 & 340.249 & 0.00 & 0.758 & 18.446 & 0.000 \\
\hline & Third equation & $\mathrm{COC}$ & $\begin{array}{l}\text { NPD_GE } \\
\text { PsyCap. }\end{array}$ & 0.682 & 0.465 & 108.971 & 0.00 & -0.144 & -2.035 & 0.043 \\
\hline & & & & & & & & 0.784 & 11.080 & 0.000 \\
\hline & & & & & & & & & 11.080 & \\
\hline \multirow{4}{*}{$\begin{array}{l}\text { NPD_EE } \\
\text { COC } \\
\text { PsyCap }\end{array}$} & First equation & $\mathrm{COC}$ & NPD_EE & 0.474 & 0.224 & 72.909 & 0.00 & 04.74 & 8.539 & 0.000 \\
\hline & Second equation & PsyCap & NPD_EE & 0.771 & 0.595 & 370.288 & 0.00 & 0.771 & 19.243 & 0.000 \\
\hline & Third equation & $\mathrm{COC}$ & $\begin{array}{l}\text { NPD_EE } \\
\text { PsyCap. }\end{array}$ & 0.679 & 0.461 & 107.517 & 0.00 & -0.116 & -1.60 & 0.111 \\
\hline & & & & & & & & 0.765 & 10.510 & 0.000 \\
\hline
\end{tabular}

The above table depicted the mediation analysis of NPD sub-constructs with COC and PsyCap. as mediating variable. The researcher analysis the mediation among NPD_LA, COC, and PsyCap. The statistical outcomes of 1 st and 2 nd equation were significant $p$ value but 3rd equation has insignificant $\mathrm{p}$ value. In the mediation analysis of NPD_GE, COC and PsyCap, all three equation has significant $p$ value, which means that there was complete mediation. In the mediation analysis of NPD_ EE, COC and PsyCap, the first and second equations 
have significant $\mathrm{p}$ value, but the third equation has insignificant $p$ value of NPD_EE (0.111) but has significant $p$ value of PsyCap. Therefore, there was partial mediation among NPD_EE, COC and PsyCap.

In a nutshell, NPD and their sub-constructs have linear regression with $\mathrm{COC}$ but the presence of mediation variable PsyCap has partially intervening the relationship of NPD and COC.

NPD impact on COC with mediating role of PsyCap (self-efficacy, hope, optimism, resilience) sub-constructs has complete mediation role expect selfefficacy (Psy_SE).

\section{Results and discussion}

The current research study evaluate the impact of narcissism personality disorder on organizational cynicism. From past theories and research work, researcher deduce the following question and hypothesis to analysis the association between NPD and COC:

Q1: What are the effect of narcissism personality

\begin{tabular}{|c|c|c|c|c|c|c|c|c|c|c|}
\hline & & $\begin{array}{l}\text { Dependent } \\
\text { variable }\end{array}$ & $\begin{array}{l}\text { Independent } \\
\text { variable }\end{array}$ & $R^{2}$ & Adj. $R^{2}$ & $F$ & $p$ & $\beta$ & $t$ & $p$ \\
\hline NPD & First equation & $\mathrm{COC}$ & NPD & 0.505 & 0.255 & 86.306 & 0.00 & 0.505 & 9.290 & 0.000 \\
\hline $\mathrm{COC}$ & Second equation & Psy_SE & NPD & 0.807 & 0.651 & 470.107 & 0.00 & 0.807 & 21.682 & 0.000 \\
\hline \multirow[t]{2}{*}{ Psy_SE } & Third equation & $\operatorname{COC}$ & $\begin{array}{l}\text { NPD } \\
\text { Psy_SE }\end{array}$ & 0.506 & 0.256 & 43.193 & 0.00 & 0.463 & 5.028 & 0.000 \\
\hline & & & & & & & & 0.052 & 0.561 & 0.575 \\
\hline NPD & First equation & $\operatorname{COC}$ & NPD & 0.505 & 0.255 & 86.306 & 0.00 & 0.505 & 9.290 & 0.000 \\
\hline $\mathrm{COC}$ & Second equation & Psy_H & NPD & 0.521 & 0.272 & 94.081 & 0.00 & 0.521 & 9.700 & 0.00 \\
\hline \multirow[t]{2}{*}{ Psy_HPsy_H } & Third equation & $\mathrm{COC}$ & $\begin{array}{l}\text { NPD } \\
\text { Psy_H }\end{array}$ & 0.652 & 0.425 & 92.790 & 0.00 & 0.253 & 4.514 & 0.000 \\
\hline & & & & & & & & 0.483 & 8.614 & 0.000 \\
\hline NPD & First equation & $\operatorname{COC}$ & NPD & 0.505 & 0.255 & 86.306 & 0.00 & 0.505 & 9.290 & 0.000 \\
\hline $\mathrm{COC}$ & Second equation & Psy_OPT & NPD & 0.779 & 0.608 & 390.197 & 0.00 & 0.779 & 19.753 & 0.000 \\
\hline \multirow[t]{2}{*}{ Psy_OPT } & Third equation & $\operatorname{COC}$ & $\begin{array}{l}\text { NPD } \\
\text { Psy_OPT }\end{array}$ & 0.528 & 0.279 & 48.607 & 0.00 & 0.312 & 3.648 & 0.000 \\
\hline & & & & & & & & 0.248 & 2.895 & 0.004 \\
\hline NPD & First equation & $\mathrm{COC}$ & NPD & 0.505 & 0.255 & 86.306 & 0.00 & 0.505 & 9.290 & 0.000 \\
\hline $\mathrm{COC}$ & Second equation & Psy_RE & NPD & 0.742 & 0.550 & 308.104 & 0.00 & 0.742 & 17.553 & 0.000 \\
\hline \multirow[t]{2}{*}{ Psy_RE } & Third equation & $\mathrm{COC}$ & $\begin{array}{l}\text { NPD } \\
\text { Psy_RE }\end{array}$ & 0.823 & 0.678 & 263.777 & 0.00 & -0.214 & -3.998 & 0.051 \\
\hline & & & & & & & & 0.969 & 18.137 & 0.000 \\
\hline
\end{tabular}

The above table depicted the mediation analysis of NPD with $\mathrm{COC}$ and four sub-constructs of PsyCap as mediating variable. The researcher analysis the mediation among NPD, COC and Psy_SE. The statistical outcomes of first and second equations were significant $p$ value, but the third equation has insignificant $p$ value. In the mediation analysis of NPD, COC, and Psy_H, all three equations have significant $p$ value, which means that there was complete mediation. In the mediation analysis of NPD, COC, and Psy_OPT, all three equation has significant $p$ value, which means that there was complete mediation. In the mediation analysis of NPD, COC, and Psy_SE, all three equation has significant $p$ value, which means that there was complete mediation.

In a nutshell, NPD have liner regression with COC, but the presence of mediation variable PsyCap and their disorder (NPD) on cognitive organization cynicism $(\mathrm{COC})$ ?

The term narcissism demonstrate the self-praise, selfesteem, and abnormal personality of individual. When persons having narcissism disorder in their personality especially in nurses profession. The quality of patients care significantly damage and such personnel responsible for negative actions toward their organizations. Narcissism personality disorder has three sub-constructs: Leadership/Authority, Grandiose Exhibitionism, and Entitlement/Exploitativeness [1].

Malik and Khan [29] conducted a comparative study of public and private banks of Pakistan to measure the bosses' narcissism behavior at workplace and the role of employee psychological contacts. The findings depicted that there was strong correlation between leader 
narcissism and employee psychological contacts. The leader narcissism determining the organizational climate and enhanced sanity at workplace. These findings support researcher view that individual narcissism significantly affect the organizational climate. Grijalva and Harms [18] study the narcissism in the context of counterproductive work behavior and leadership. The analysis depicted that narcissistic behavior of leaders predicts the counterproductive work attitude in the followers. The prospective of this research the support the researcher viewpoint that persons having narcissism characteristic will ultimately harm the follower behavior and finally distract the organizational objectives.

Erkutlu and Chafra [15] studied the leader narcissism and subordinate embeddedness with moderating role of moral attentiveness and behavioral integrity in hotel industry employees. The findings portray that leaders narcissism promotes unethical behavior in the coworker and finally harms the organizational culture and objectives. This study support current theme of research that narcissism behavior of individual promotes adverse behavior among the coworkers. In another study, Erkutlu and Chafra [15] analyzes the leader's narcissism and organizational cynicism in healthcare organization with mediating role of psychological strain. The unit of analysis in this study was certified nurses in Turkey. The statistical results depicted that there was positive and significant association between organizational cynicism and leader's narcissism. In the presence of psychological capital, the association between narcissism and organizational cynicism was weak. The outcomes of this study supports the current research outcomes that there was positive and significant correlation exist.

The statistical results and past research work confirmed that narcissism personality disorder has positive and significant association with organizational cynicism.

The psychological capital has four sub-constructs: self-efficacy, hope, optimism, and resilience. The role of psychological capital was mediating in the relationship between narcissism personality disorder and cognitive organizational cynicism.

\section{Q2: What is the role of psychological capital to intervene the association between narcissism per- sonality disorder (NPD) and cognitive organization cynicism (COC)? \\ Cognitive Organization Cynicism (COC) is medi- ated by Psychological Capital (PS).}

The psychological capital has positive impact on positive expectations, future success and determination. PsyCap. Eliminate adverse individual feelings toward their organizations [10]. Yim et al. [38] analysis the association between occupational stress and turnover intention among nurses in Korea with psychological capital as mediating variable. The statistical results depicted that all study variables have significant correlation and the role of psychological capital was partial mediating between the association of occupational stress and turnover. The findings of this study support researcher statistical outcomes that psychological capital has partial mediating role.

Li et al. [27] conducted a cross-sectional study to discuss the mediating role of psychological capital between the relationship of occupational stress and job burnout among banking sector employees in China. The gender (male/female) factor has difference role in psychological capital. In female banking employees, the role of psychological capital was partial mediating, and in male banking employees, it has complete mediating role. They suggested that psychological capital has potential to lessen the employees negative behavior, stress level and job burnout among banking employees more importantly in female banking employees. The findings and suggestions were portray the basic concept of this research work that PsyCap has potential to overcome follower's negative belief in the presence of narcissism leaders at workplace.

Turgut and Agun [36] investigate the mediating role of psychological capital and employee voice in the relationship of organizational justice and organizational cynicism. The conclusion depicted that negative relationship found between organizational justice and organizational cynicism. The mediating role of psychological capital and employee's voice were not confirmed. Mohagheghi et al. [30] discussed the mediating role of psychological capital and job resources between the relationship of job demands and job burnout. The findings confirmed that job demands were affected by job resources and job burnout, psychological capital has mediating role in the relationship. Both studies have distinguish results, and in the current study, psychological capital has partial mediating role between the relationship of narcissism personality disorder and cognitive organizational cynicism. But sub-constructs of psychological capital played complete and partial mediating role in the relationship. Hence, the mediating role of PsyCap can depend on organizational culture and bosses behavior toward their subordinates.

Shang Guan et al. [35] conducted a cross-sectional study to find out the mediating role of psychological capital between the association of occupational stress and job satisfaction in Chinese society. The findings described that partial mediate the relationship between occupational stress and job satisfaction. There was a negative correlation found between occupational stress and job satisfaction.

From the above discussion, psychological capital has complete or partial mediating role. In the current research, the role of psychological capital is partial 
mediating and accept that $\mathrm{H}_{2}$ that PsyCap mediates the positive association between narcissism personality disorder and cognitive organizational cynicism.

\section{Conclusion}

The theme of this research work is to analysis the narcissism personality disorder in nurses and their impact on cognitive organizational cynicism with mediating role of psychological capital. The review of past research work and statistical results of this study concluded that narcissism personality disorder has significant positive association with cognitive organizational cynicism. It means that nurses having narcissistic personality having their personal goals and present their personality at every level. In this situation, the follower believes that in the presence of such narcissistic person's, organization cannot able to achieve their objectives. The role of psychological capital is mediating to minimize the negative employee's behavior toward their bosses and organization.

\section{Implications of the study}

In the light of findings, the current research work has implications at individual and organization levels. This research work will become as foundation stone to formulate strategies to overcome the organization cynicism in nursing profession. Furthermore, the organization formulate selection process more affective to find those candidates having narcissism disorder. A well-organized social and electronic media awareness session should be designed to build the constructive image of nursing profession.

At organization level, the hospital management demonstrate authoritarian leadership style. In the light of this study, training session will be organized to address the other leadership style in order to build friendly work environment.

\section{Limitations}

In the current research study, researcher try to cover up the broad range of factors that affect the phenomena of narcissism and organizational cynicism in nursing profession. In spite of that, researcher face the following constraints during the research work these limitations must be avoided in future research work. Theoretically, the results of this study are based on a single construct of organizational cynicism. Hence, researcher was unable to find the full or partial mediation effect on other subconstructs of organizational cynicism. Methodologically, researcher adopted simple random sampling technique, the access of nurses personal information was restricted by the hospital management. Contextually, researcher collect responses from nurses performing their duty in primary healthcare hospitals of public sector. Therefore, the issue of generalizability of the current study on specialized healthcare hospitals and private sector. Another constraint of this study is that responses were collected form nurses staff only, while other hospitals staff like doctors, allied, and paramedical staff were not considered.

\begin{abstract}
Abbreviations
Psy Cap: psychological capital; NPI: narcissism personality inventory; NPD: narcissism personality disorder; COC: cognitive organization cynicism; CPC-12: Compound Psychological Capital Scale-12; CEO: chief executive officer; DHQ: divisional headquarters; THQ: tehsil headquarters; RHC: rural health clinic; SPSS: statistical packages of social sciences; NPD_LA: Narcissism Personality Disorder_Leadership/Authority; NPD_GE: Narcissism Personality Disorder_Grandiose Exhibitionism; NPD_EE: Narcissism Personality Disorder_Entitlement/ Exploitativeness; PSY_SE: Psychological_Self-Efficacy; PSY_H: Psychological_ Hope; PSY_RE: Psychological_Resilience; PSY_OP: Psychological_Optimism.
\end{abstract}

\section{Acknowledgements}

We would like to thanks ALLAH Almighty for His blessing.

\section{Authors' contributions}

IS found the research gap, problem statement, research model, and title of paper and was a major contributor in writing the manuscript. SH conducted the literature review and was a major contributor in writing the manuscript. MBM wrote up the methodology, analysis, and conclusion section and was a major contributor in writing the manuscript. AR collect the data from respondents. AS run the analysis of paper. FN done proofreading and editing of paper. All authors read and approved the final manuscript.

\section{Funding}

The authors declare that there is no funding agency was involved during all the research process. Authors managed themselves all the research funds.

\section{Availability of data and materials}

The datasets used and/or analyzed during the current study are available from the corresponding author on reasonable request. The datasets generated and/or analyzed during the current study are not publicly available due anonymity issues but are available from the corresponding author on reasonable request.

\section{Competing interests}

The authors declare that they have no competing interests.

\section{Author details}

${ }^{1}$ University of Central Punjab (UCP), Lahore, Pakistan. ${ }^{2}$ COMSATS University Islamabad, Islamabad, Pakistan. ${ }^{3}$ Universiti Sultan Zainal Abidin (UniSZA),

Gong Badak Campus, 21300 Kuala Nerus, Terengganu, Malaysia.

Received: 28 October 2019 Accepted: 13 August 2020

Published: 29 August 2020

\section{References}

1. Ackerman RA, Witt EA, Donnellan MB, Trzesniewski KH, Robins RW, Kashy DA (2011) What does the narcissistic personality inventory really measure? Assessment 18(1):67-87

2. Adler A, Seligman ME (2016) Using wellbeing for public policy: theory, measurement, and recommendations. Int J Wellbeing. https://doi. org/10.5502/ijw.v6i1.429

3. Aslam U, Arfeen M, Mohti W, Rahman U (2015) Organizational cynicism and its impact on privatization (evidence from federal government agency of Pakistan). Transforming Government: People, Process and Policy

4. Baron RM, Kenny DA (1986) The moderator-mediator variable distinction in social psychological research: conceptual, strategic, and statistical considerations. J Person Soc Psychol 51 (6):1173 
5. Batool T (2014) The dimensions of psychological capital and their relationship with employee engagement. GRIN Verlag, Munich

6. Bell JB (2016) Cynicism and narcissism: masking the good life? EWU Masters Thesis Collection

7. Braun S (2017) Leader narcissism and outcomes in organizations: a review at multiple levels of analysis and implications for future research. Front Psychol 8:773

8. Byrd ME (2006) Social exchange as a framework for client-nurse interaction during public health nursing maternal-child home visits. Public Health Nurs 23(3):271-276

9. Carlson KS, Gjerde PF (2009) Preschool personality antecedents of narcissism in adolescence and young adulthood: a 20-year longitudinal study. J Res Person 43(4):570-578

10. Cavus MF, Gokcen A (2015) Psychological capital: definition, components and effects. J Educ Soc Behav Sci. https://doi.org/10.9734/BJESB S/2015/12574

11. Çınar O, Karcıoğlu F, Aslan I (2014) The relationships among organizational cynicism, job insecurity and turnover intention: a survey study in Erzurum/Turkey. Procedia Soc Behav Sci 150:429-437

12. Coffey JK, Wray-Lake L, Mashek D, Branand B (2016) A multi-study examination of well-being theory in college and community samples. J Happiness Stud 17(1):187-211

13. Dean JW Jr, Brandes P, Dharwadkar R (1998) Organizational cynicism. Acad Manag Rev 23(2):341-352

14. Erkutlu H, Chafra J (2016) Impact of behavioral integrity on workplace ostracism. J Appl Res Higher Educ. https://doi.org/10.1108/JARHE $-01-2015-0007 / f u l l / h t m$

15. Erkutlu H, Chafra J (2017) Leaders' narcissism and organizational cynicism in healthcare organizations. Int J Workplace Health Manag

16. Esmaeilzadeh P, Sambasivan M, Nezakati H, Kumar N (2013). How social exchange in hospitals can influence adoption of clinical IT? J Bus Adm Educ 2(2)

17. Forsyth DR, Banks GC, McDaniel MA (2012) A meta-analysis of the Dark Triad and work behavior: a social exchange perspective. J Appl Psychol 97(3):557

18. Grijalva E, Harms PD (2014) Narcissism: an integrative synthesis and dominance complementarity model. Acad Manag Perspect 28(2):108-127

19. Grijalva E, Newman DA (2015) Narcissism and counterproductive work behavior (CWB): meta-analysis and consideration of collectivist culture, big five personality, and narcissism's facet structure. Appl Psychol 64(1):93-126

20. Holthausen J (2010). Scientific review of the social exchange theory and its contribution to solving purchasers' decision making issues. University of Twenty

21. Işı ÖG (2014) Organizational cynicism a study among advertising agencies. Akdeniz Üniversitesi İletişim Fakültesi Dergisi 22:130-151

22. Jafree SR (2017) Workplace violence against women nurses working in two public sector hospitals of Lahore, Pakistan. Nurs Outlook 65(4):420-427

23. Johannesson P, Perjons E (2014) An introduction to design science. Springer, Berlin

24. Kalağan G, Aksu MB (2010) Organizational cynicism of the research assistants: a case of Akdeniz University. Procedia Soc Behav Sci 2(2):4820-4825
25. Kaygin E, YilmazT, Gulluce A, Salik N (2017) A research for determining the relationship between the organizational cynicism and the organizational commitment. Manag Organ Stud 4(1):1-9

26. Krejcie RV, Morgan DW (1970) Determining sample size for research activities. Educ Psychol Meas 30(3):607-610

27. Li X, Kan D, Liu L, Shi M, Wang Y, Yang X, Wu H (2015) The mediating role of psychological capital on the association between occupational stress and job burnout among bank employees in China. Int J Environ Res Public Health 12(3):2984-3001

28. Lorenz T, Beer C, Pütz J, Heinitz K (2016) Measuring psychological capital: construction and validation of the compound PsyCap scale (CPC-12). PLoS ONE 11(4):e0152892

29. Malik K, Khan FN (2013) Narcissistic leadership at workplace and the degree of employee psychological contract: a comparison of public and private sector organizations in Pakistan. Int J Econ Bus Manag Stud 2(3):116-127

30. Mohagheghi H, Parto E, Nahalgar P, Hosseini SM, Farahbakhsh K (2015) The mediating role of job resources and psychological capital in the job demands-job burnout relationship. J Appl Environ Biol Sci 5(7):90-97

31. Munir Y, Ghafoor MM, Rasli AM (2016) Exploring the relationship of horizontal violence, organizational cynicism and turnover intention in the context of social exchange theory. Int J Hum Rights Healthc. https://doi. org/10.1108/IJHRH-08-2016-0014/full/html

32. Polatcan M, Titrek O (2014) The relationship between leadership behaviors of school principals and their organizational cynicism attitudes. Procedia-Soc Behav Sci 141:1291-1303

33. Redmond MV (2015) Social exchange theory

34. Seligman M (2011) Flourish: a visionary new understanding of happiness and well-being. Policy 27(3):60-61

35. Shang Guan C-Y, Li Y, Ma H-L (2017) The mediating role of psychological capital on the association between occupational stress and job satisfaction among township cadres in a specific province of China: a cross-sectional study. Int J Environ Res Public Health 14(9):972

36. Turgut T, Agun $\mathrm{H}$ (2016) Journal of behavior at work. J Behav Work 1:1

37. Wang Y, Liu L, Wang J, Wang L (2012) Work-family conflict and burnout among Chinese doctors: the mediating role of psychological capital. J Occup Health 54(3):232-240

38. Yim H-Y, Seo H-J, Cho Y, Kim J (2017) Mediating role of psychological capital in relationship between occupational stress and turnover intention among nurses at veterans administration hospitals in Korea. Asian Nurs Res 11(1):6-12

39. Youssef-Morgan CM, Luthans F (2015) Psychological capital and wellbeing. Stress Health 31(3):180-188

\section{Publisher's Note}

Springer Nature remains neutral with regard to jurisdictional claims in published maps and institutional affiliations.

\section{Submit your manuscript to a SpringerOpen ${ }^{\circ}$ journal and benefit from:}

- Convenient online submission

- Rigorous peer review

- Open access: articles freely available online

- High visibility within the field

- Retaining the copyright to your article

Submit your next manuscript at $\boldsymbol{\nabla}$ springeropen.com 